\title{
Pulmonary Vascular Disease in Shunted and Nonshunted Patients with Tetralogy of Fallot
}

\author{
Shigeo Yamaki \\ The Department of Thoracic and Cardiovascular Surgery, \\ Tohoku University School of Medicine, Sendai 980
}

\begin{abstract}
YAMAKI, S. Pulmonary Vascular Disease in Shunted and Nonshunted Patients with Tetralogy of Fallot. Tohoku J. Exp. Med., 1990, 162 (2), 109-119 - Histometric analysis of pulmonary vascular disease was performed in 13 shunted and 21 nonshunted patients with tetralogy of Fallot, and in 29 normal controls. There was no significant difference in the medial thickness of the small pulmonary arteries between cases of tetralogy of Fallot and normal controls, but the media in shunted cases of tetralogy of Fallot were thicker than in the nonshunted cases. Intimal fibrosis, regarded as organized thrombi, and thrombi of small pulmonary arteries were observed generally after 4 years of age in both the shunted and nonshunted cases of tetralogy of Fallot. Intimal proliferation of musculoelastosis which was formed of longitudinal smooth muscle bundles and elastic fibers was characteristic in shunted patients, especially after the central palliation procedure, Waterston anastomosis or modified Blalock-Taussig (BT) anastomosis using the Gore-Tex tube graft. However, it was not usually seen in the BT anastomosis cases. Unexpected pulmonary hypertension due to the shunt operation is thought to be the cause of musculoelastosis, because musculoelastosis was observed even in a patient with pulmonary hypertension only 3 weeks following surgery. We therefore recommend the original BT anastomosis as the shunt procedure. When considering the use of other shunt operations in which there is a possibility of placing a pressure load on the pulmonary vascular bed, attention must be given to the size of the anastomosis or artificial tube graft.

pulmomary vascular disease; tetralogy of Fallot; pulmonary hypertension; musculoelastosis ; thrombi
\end{abstract}

Pulmonary vascular disease (PVD) in cases of tetralogy of Fallot is reported to be mainly due to thrombi (Heath et al. 1958; Ferencz 1960), but it has occasionally been pointed out that plexogenic arteriopathy also develops following shunt surgery (Wagenvoort et al. 1960 ; Hofschire et al. 1977). The present study is a comparison of PVD seen in patients who have undergone shunt operations and those who have not. Although it was found that both groups had

Received August 18, 1990; revision accepted for publication August 30, 1990.

Address for reprints : Dr. Shigeo Yamaki, the Department of Thoracic and Cardivascular Surgery, Tohoku University School of Medicine, Seiryo-machi 1-1, Aoba-ku 980, Sendai, Japan. 
PVD due to thrombi, specific intimal lesions of the small pulmonary arteries were also found in patients who had undergone shunt surgery. Such lesions differ from the plexogenic arteriopathy previously reported and their incidence is related to the operative methods used in the shunt operations. The clinical significance of these findings is discussed.

\section{Materials and Methods}

Twenty-one patients with tetralogy of Fallot between the ages of 9 days and 42 years (mean of 5.8 years) who did not receive shunt surgery and 13 patients between the ages of 5 and 16 years (mean of 9.0 years) who did undergo such surgery were included in this study (Table 1 and 2). Three of the patients not receiving shunt surgery had patent ductus arteriosus (PDA) in addition to tetralogy of Fallot. Three other patients not undergoing shunt surgery and 8 of the patients who received such treatment had extreme types of tetralogy of Fallot.

Of the cases of shunt surgery, the Blalock-Taussig (BT) procedure was used in 6 , a modified BT (MBT) procedure employing an artificial tube graft was used in 3, central palliation involving only reconstruction of the outflow tract of the right ventricle was employed in 2, and the Waterston procedure was used in 2. For control purposes, the medial thickness of small pulmonary arteries was measured in 29 normal autopsy cases without cardiac disease between the ages of 3 days and 50 years.

The clinical data came from 25 autopsy cases ( 8 shunted and 17 non-shunted cases) and from 9 biopsy cases (5 shunted and 4 non-shunted cases). The biopsies were done at the time of shunt operation or total correction. In order to select the region with the severest lesion in the autopsy cases, 15 samples of lung tissue were taken from the operated side in the BT cases, and 15 samples were taken from the side in which main or peripheral pulmonary arterial stenosis was not seen in the Waterston and central palliation cases.

Among the biopsy cases without shunt operation, lung tissue was obtained from the right median lobe and approximately 30 step sections of $50 \mu \mathrm{m}$ thickness were made. Staining was done using the Elastica-Goldner method.

The thickness of the media at the radius of $100 \mu \mathrm{m}$ in small pulmonary arteries was measured using a previously reported method of assessment (Yamaki and Tezuka 1976; Yamaki and Wagenvoort 1981), and given in terms of mean \pm S.D. Comparison of the thickness of the media was made among the normal control cases and shunted or nonshunted cases in various age groups and differences between mean values were analyzed using student $t$-test, and a $p$ value less than 0.05 was accepted as the level of significance.

The intimal lesions were divided into three types: (1) fibrous proliferation, (2) thrombi of small pulmonary arteries, and (3) musculoelastosis consisting of proliferation of longitudinal smooth muscle bundles and elastic fibers (Yamaki et al. 1987). The ratios of such lesions to the total number of small pulmonary arteries in the histologic section were then determined.

\section{RESUlts}

\section{Thickness of the media of small pulmonary arteries}

In the normal controls, the media of the small pulmonary arteries showed thinning soon after birth and this tendency toward decreased medial thickness progressed gradually for 5 months thereafter. From around 5 months of age, the medial thickness was found to stabilize at 5-7 $\mu \mathrm{m}$.

In tetralogy of Fallot, the nonshunted cases showed a wide range of values 


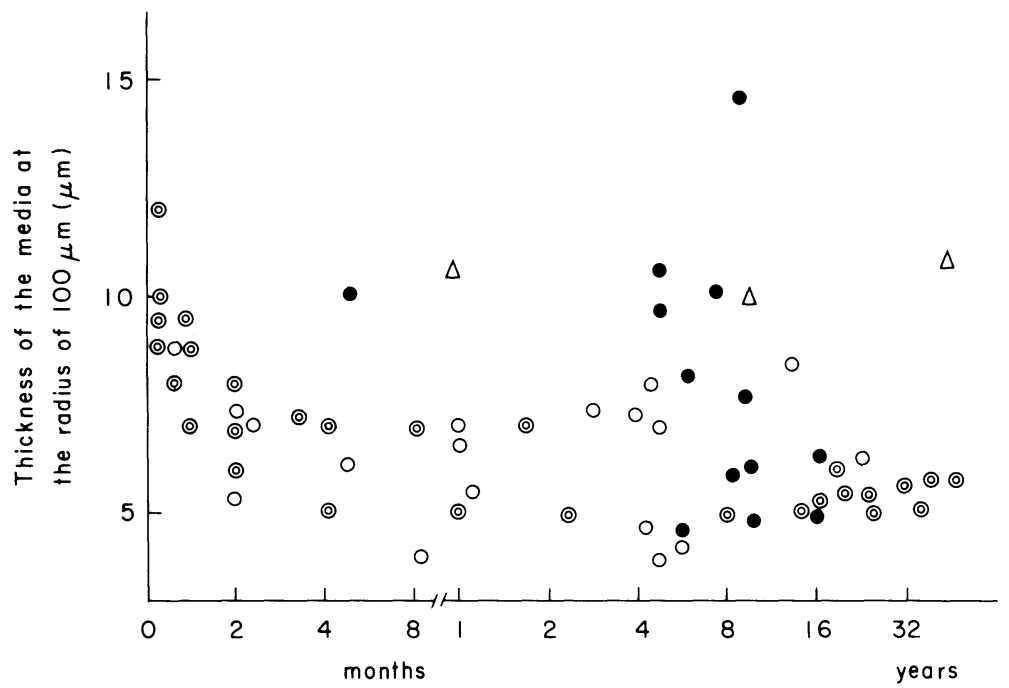

Age

Fig. 1. Thickess of the media estimated at $\mathrm{R}=100 \mu \mathrm{m}$ in small pulmonary arteries is demonstrated in reference to age. $\circ$, nonshunted TOF ; $\bullet$, shunted TOF ; $\triangle$, TOF with PDA; $\odot$, normal control. TOF, tetralogy of Fallot. PDA, patent ductus arteriosus.

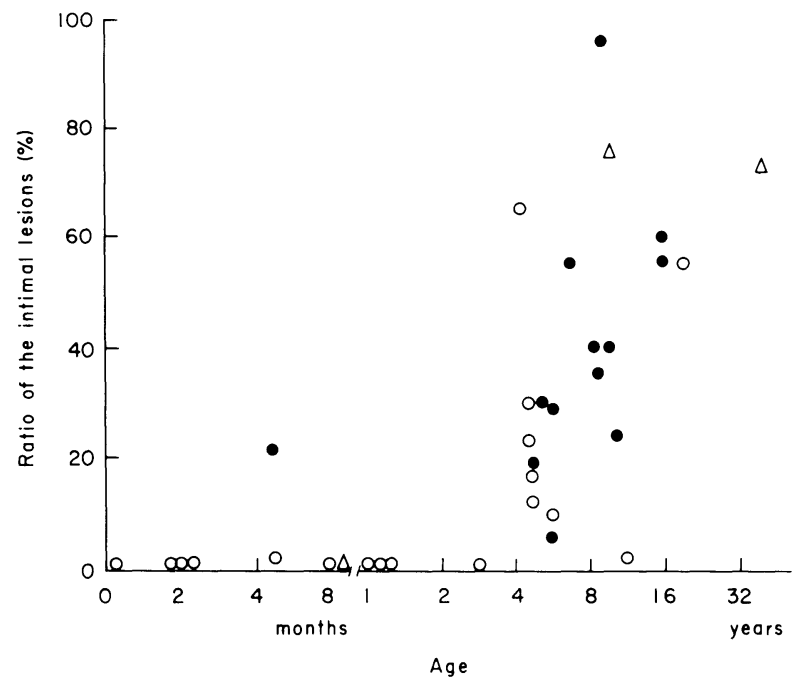

Fig. 2. Ratio of small pulmonary arteries with intimal lesions for shunted and nonshunted cases is plotted against age. Intimal lesions of the shunted cases were significantly higher $(p<0.05)$ than those of the non shunted cases 4 years of age or older. Symbols are the same as in Fig. 1. 
from 3.8 to $8.5 \mu \mathrm{m}$ after the age of 5 months, but the mean value $(6.6 \pm 1.8 \mu \mathrm{m})$ was not significantly different from that of the normal controls $(6.8 \pm 1.8 \mu \mathrm{m})$ (Fig. $1)$.

In contrast, in the shunted cases and those with tetralogy of Fallot with PDA, the medial thickness was, respectively, $8.0 \pm 2.9 \mu \mathrm{m}$ and $10.4 \pm 0.4 \mu \mathrm{m}$, indicating a notable tendency toward a thickening of the media.

\section{Intimal lesions of the small pulmonary arteries}

Fig. 2 shows a comparison of the ratio of small pulmonary arteries with intimal lesions for the shunted and nonshunted cases according to age. Among the patients not undergoing surgery, few intimal lesions were found in those less than 3 years of age, although such lesions were relatively frequent in the older patients. Among the shunted cases, intimal lesions were seen in $20 \%$ of the small pulmonary arteries, even in a 5 -month-old patient, a ratio which was significantly higher $(p<0.05)$ than that seen in the nonshunted cases 4 years of age or older.

The intimal lesions among the nonshunted cases were thrombi (Fig. 3 ) in 9 cases, but all 9 were over the age of 4 (Table 1). Fibrous thickening of the intima (Fig. 4) was found in 11 cases, but there were no cases with concentric lesions and all showed cushion-like or mountain-like protrusions into the vascular lumen.

Characteristic of the intimal lesions in the shunted patients was the fact that 8 of the 13 showed musculoelastosis due to proliferation of longitudinal smooth muscle bundles and elastic fibers (Table 2). The lesions were severest in the

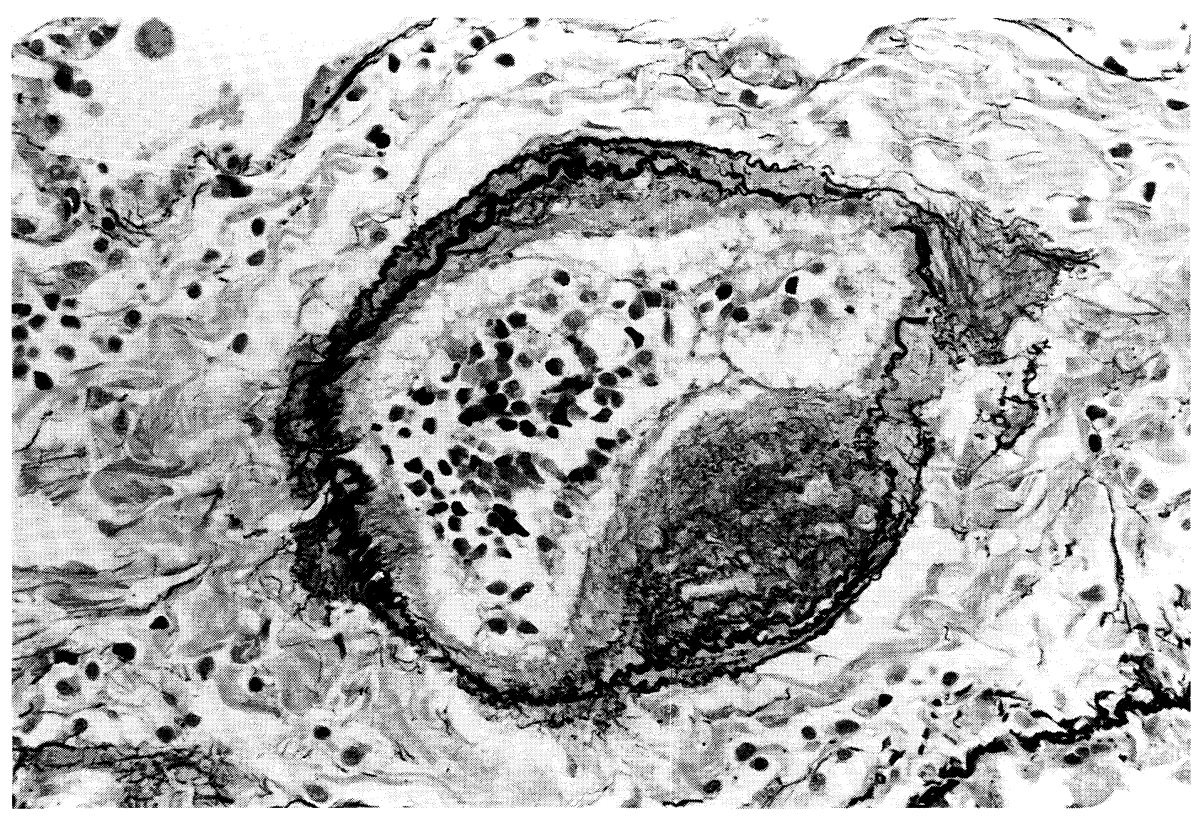

Fig. 3. Thrombi of small pulnonary artery in Case 12. 


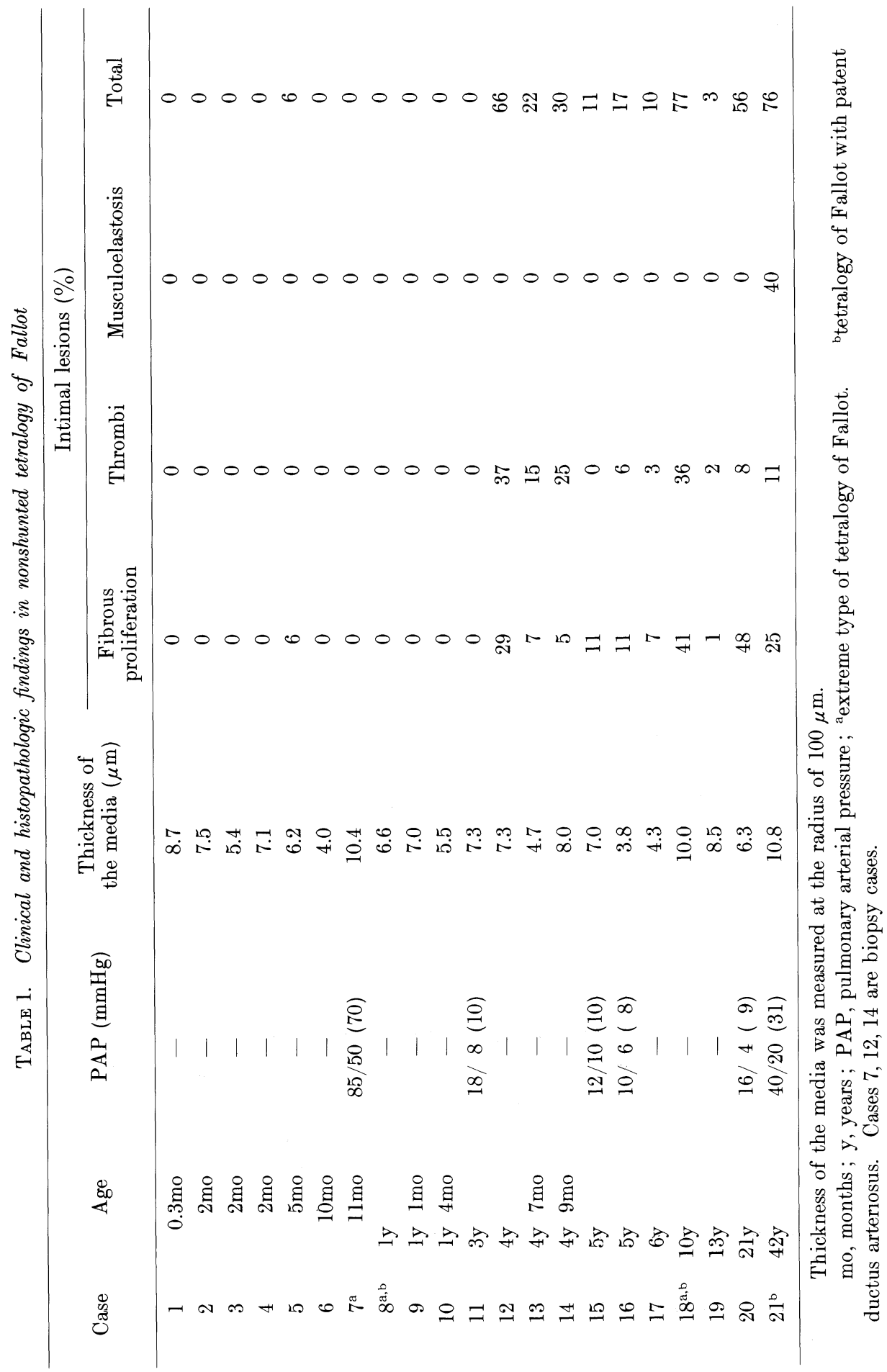




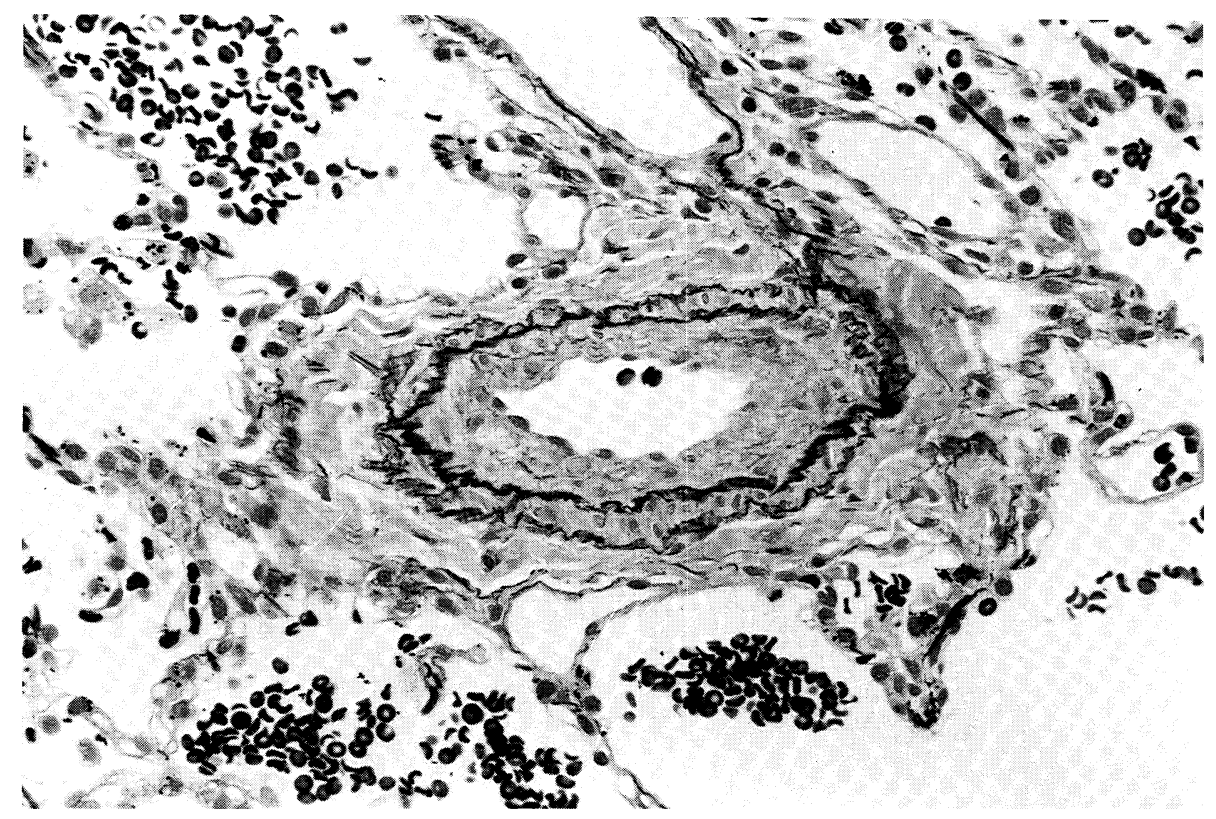

Fig. 4. Fibrous proliferation of the intima in Case 19.

central palliation cases, with one 9-year-old patient (Case 34) suffering complete occlusion of the vascular lumen (Fig. 5), and ultimately death following closure of the ventricular septal defect. This case exhibited severe pulmonary hypertension of $103 / 21(60) \mathrm{mmHg}$.

Musculoelastosis was also observed in all of 3 cases undergoing the MBT shunt. In Case 28, which had the highest degree of musculoelastosis, a Gore-Tex tube graft $5 \mathrm{~mm}$ in diameter was used and postoperatively mild pulmonary hypertension (a pulmonary arterial pressure of $40 / 16(26) \mathrm{mmHg}$ ) was seen. In the remaining 2 cases undergoing the MBT procedure, Gore-Tex tube grafts $4 \mathrm{~mm}$ in diameler were used.

In both of the cases undergoing Waterston anastomosis, the postoperative angiography showed occlusion of a part of the anastomosis, so that the relationship between the operative method and musculoelastosis remains unclear. Since only 2 of the 6 cases undergoing the BT procedure were found postoperatively to have musculoelastosis, it is thought to be the operative method least likely to lead to such lesions. Thrombi were found in 9 of the shunted cases, but they were found regardless of the operative technique in cases more than 5 years of age and are consequently thought to have been present prior to surgery. Fibrous proliferation of the intima was found in 12 cases, and such lesions were thought to be organized thrombi or organized musculoelastosis.

Concerning the relationship between intimal lesions and the length of time following the shunt operation, it is seen that relatively few lesions developed 
Pulmonary Vascular Disease

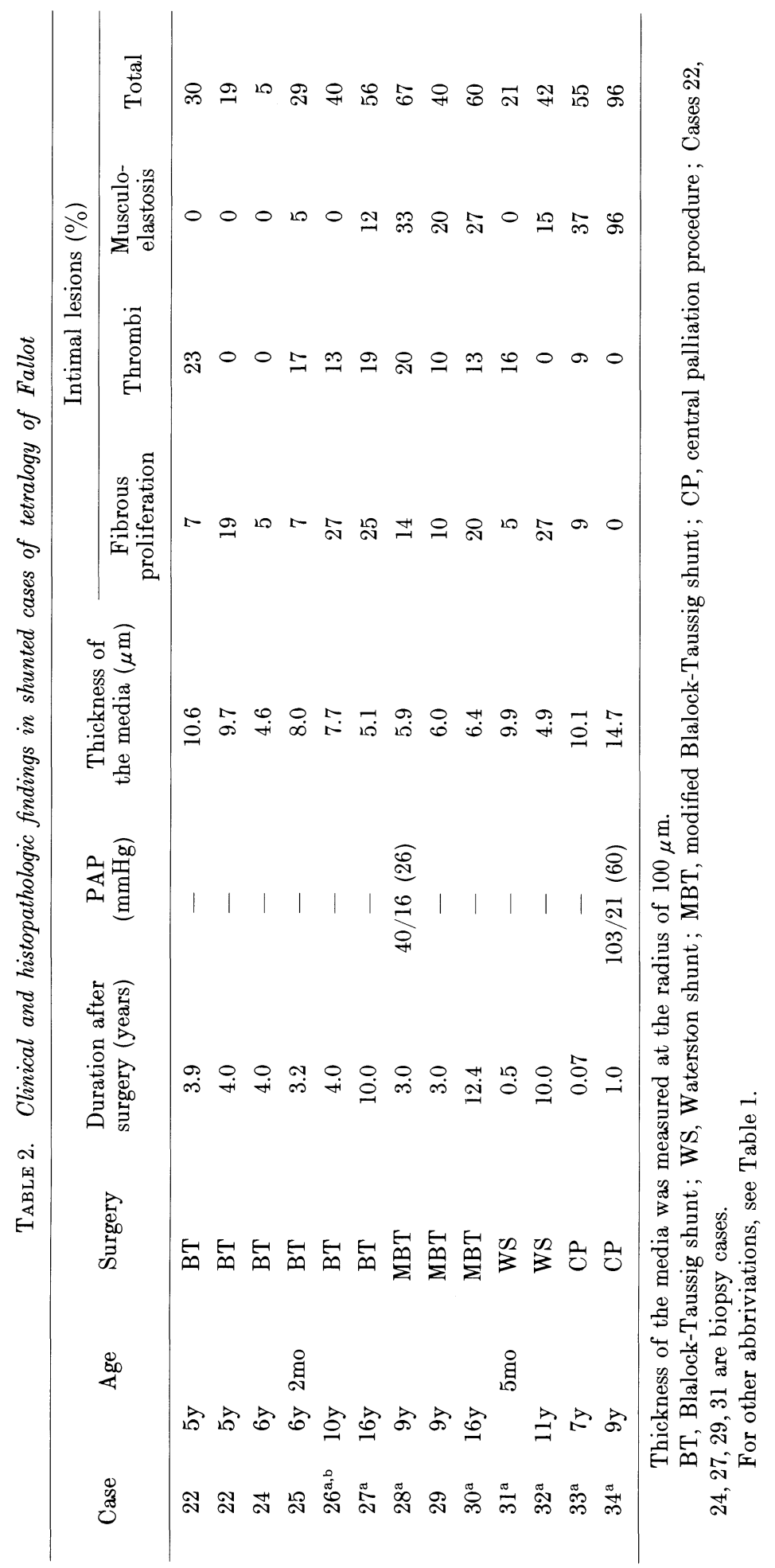




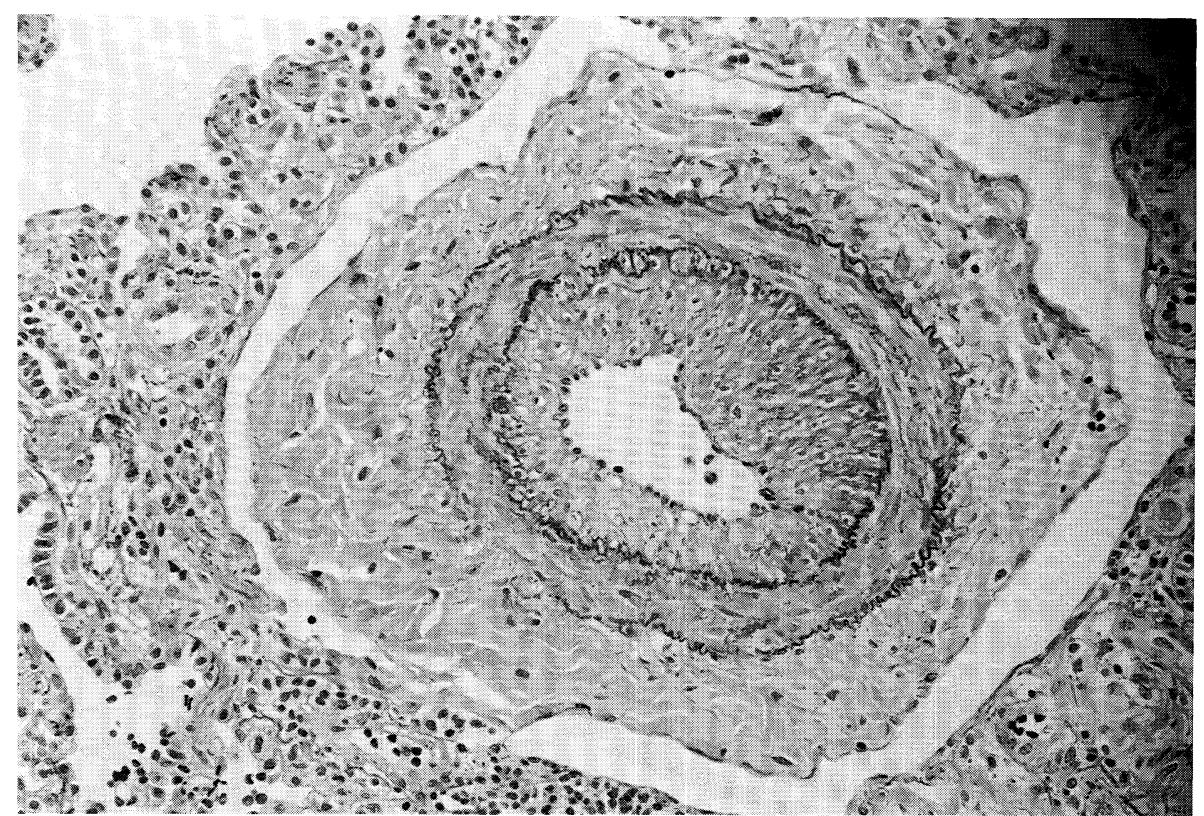

Fig. 5. Musculoelastosis seen in Case 34. Note marked proliferation of the longitudinal smooth muscle bundles and elastic fibers.

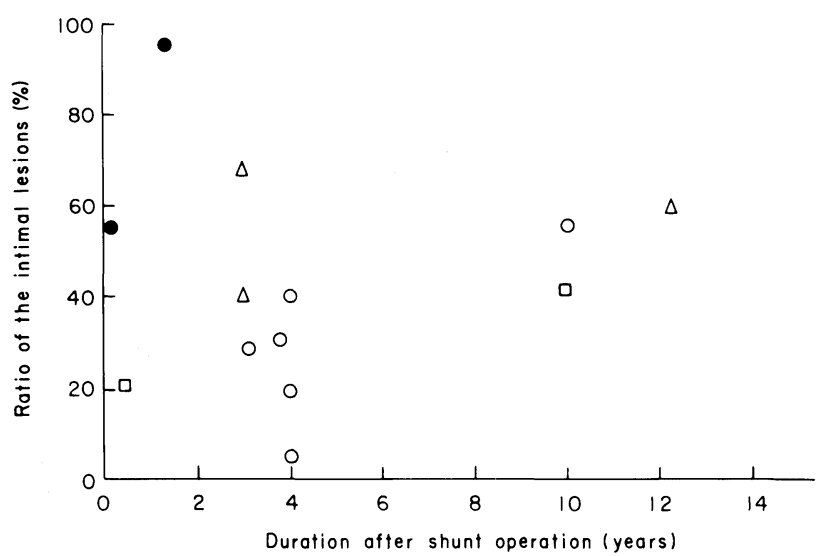

Fig. 6. Ratio of small pulnonary arteries with intimal lesions and the length of time following the shunt operation.

, BT shunt; $\triangle$, MBT shunt; 二, Waterston shunt; •, central palliation procedure.

among the BT cases even after several years. However, there was a high incidence of intimal lesions even after a short period among the cases undergoing central palliation (Fig. 6). Particularly noteworthy in this regard was the severe musculoelastosis in Case 33 seen only 3 weeks following central palliation 
(Table 2).

\section{Discussion}

Several studies have previously reported on the thickness of the media of small pulmonary arteries in cases of tetralogy of Fallot, but consensus has not been reached (Wagenvoort et al. 1967 ; Hislop and Reid 1973 ; Shapira et al. 1982).

We have measured medial thickness using a method in which the internal elastic lamina is presumed to be completely stretched. With such a technique, the medial thickness of small pulmonary arteries in normal controls is found to decrease following birth and to stabilize at 5-7 $\mu \mathrm{m}$ after the age of 5 months. In tetralogy of Fallot, the medial thickness is found to vary greatly from 3.8 to 8.5 $\mu \mathrm{m}$, but the mean value was not significantly different from that of normal controls. It is said that the media of small pulmonary arteries show hypertrophy after the shunt operation (Shapira et al. 1982), and indeed such a tendency was seen in our series of patients.

The presence of thrombi and fibrous proliferation of the intima in the small pulmonary arteries in cases of tetralogy of Fallot have been reported by many authors (Rich 1948). Wagenvoort et al. (1967) have suggested that the fibrous proliferation seen in tetralogy of Fallot is probably organized thrombi. Histopathologically, it is of course difficult to discriminate between organized thrombi and fibrous proliferation strictly, but the intimal lesions which we observed were clearly different from the concentric laminar type lesions normally seen in plexogenic pulmonary arteriopathy. Since they were cushion-like, protruded into the vascular lumen and were shaped like thrombi, they were thought to have their origins in thrombi.

In cases of secundum atrial septal defect with thrombic PVD, the postoperative course is said to be good (Yamaki et al. 1986, 1987). In our series of tetralogy of Fallot patients as well, the postoperative course following total correction was favorable, even in Cases 12, 14, 22 and 31 where severe thrombi were found. We therefore conclude that, although mild pulmonary hypertension remained in some cases postoperatively, it did not have a great influence on the final outcome.

It was characteristic of those cases undergoing the shunt operation that, postoperatively, musculoelastosis, including proliferation of longitudinal muscle fibers and elastic fibers, was often found. Such musculoelastosis is thought to be the cause of the higher incidence of intimal lesions, in comparison with the incidence in the nonshunted cases.

Musculoelastosis was severest in the cases undergoing central palliation, but was infrequent in those undergoing the BT procedure. In other words, it was severe after operations which are more likely to lead to postoperative pulmonary hypertension. In light of the fact that severe postoperative pulmonary hypertension was found at the time of cardiac catheterization in Cases 28 and 34, it is 
thought that unexpected postoperative pulmonary hypertension may be the cause of the musculoelastosis. The fact that severe musculoelastosis was found as early as 3 weeks after central palliation surgery suggests that this condition appears soon after the shunt operation which causes abrupt pulmonary hypertension.

When pulmonary hypertension suddenly develops in the pulmonary vascular bed, where the thickness of media is normal, the media of small pulmonary vessels will hypertrophy and the vessel walls will adapt to the high intra-arterial pressure. However, since 3 or 4 weeks are required for medial hypertrophy to occur (Yamaki et al. 1980), it is likely that, as a defense mechanism, longitudinal muscle fibers will appear.

There has previously been a report of the terminal stages of plexogenic pulmonary arteriopathy, such as plexiform lesions, following shunt operations (Wagenvoort et al. 1960), but there have been a few reports of musculoelastosis. In atrial septal defect with pulmonary hypertension, the presence of musculoelastosis has been pointed out (Yamaki and Wagenvoort 1981), and it is known that complication with plexiform lesions has a bad influence on prognosis (Yamaki et al. 1987). These facts suggest that in cases such as our Case 34, if the ventricular septal defect would not been closed, severe occlusive pulmonary vascular disease, such as plexiform lesions, would have probably developed.

The development of longitudinal muscle fibers is also found in mitral stenosis (Wagenvoort and Wagenvoort 1977a) and the hypoxic lung (Heath 1963), and is said to be a benign and reversible pulmonary vascular lesion (Wagenvoort and Wagenvoort 1977b). The musculoelastosis seen following shunt operations is also generally thought not to present major clinical problems. There are nonetheless some fatal cases, such as our Case 34, suggesting that musculoelastosis should be kept to a minimum. For this purpose, every step should be taken to avoid the occurrence of postoperative pulmonary hypertension.

For the shunt operation, the BT technique should be considered the first choice because of the low incidence of musculoelastosis, but when an artificial graft is to be used, care should be taken with regard to the diameter of the graft tube. When the graft diameter is too large due to the use of the central palliation procedure, it is necessary to consider techniques, such as banding, which will prevent both an increase in pulmonary arterial pressure and the appearance of longitudinal smooth muscle bundles.

\section{Acknowledgments}

I would like to thank Mr. Toshihiro Tan for his technical assistance.

\section{References}

1) Ferencz, C. (1960) The pulmonary vascular bed in tetralogy of Fallot. 1. Changes associated with pulmonary stenosis. Bull. Johns Hopkins Hosp., 106, 81-99.

2) Heath, D. (1963) Longitudinal muscle in pulmonary arteries. J. Pathol. Bacteriol., 
85, 407-412.

3) Heath, D., Dushane, J.W., Wood, E.H. \& Edwards, J.E. (1958) The aetiology of pulmonary thrombosis in cyanotic congenital heart disease. Thorax, 13, 213-217.

4) Hislop, A. \& Reid, L. (1973) Structural changes in the pulmonary arteries and veins in tetralogy of Fallot. Br. Heart $J ., 35,1178-1183$.

5) Hofschire, P.J., Rosenquist, G.C., Ruckerman, R.N., Moller, J.H. \& Edwards, J. (1977) Pulmonary vascular disease complicating the Blalock-Taussig anastomosis. Circulation, 56, 124-126.

6) Rich, A.R. (1948) A hitherto unrecognized tendency to the development of wide spread pulmonary vascular obstruction in patients with congenital pulmonary stenosis (tetralogy of Fallot). Bull. Johns Hopkins Hosp., 82, 389.

7) Shapira, N., Rosenthal, A., Heiderberger, K., Badanowski, R. \& Behrendt, D. (1982) Pulmonary vascular morphology in shunted and non shunted patients with tetralogy of Fallot. J. Thorac. Cardiovasc. Surg., 83, 650-658.

8) Wagenvoort, C.A. \& Wagenvoort, N. (1977a) Pathology of Pulmonary Hypertension, John Wiley and Sons, Inc., New York, London, pp. 177-216.

9) Wagenvoort, C.A. \& Wagenvoort, N. (1977b) Pulmonary Vascular Disease, Marcell Dekker, Inc., New York, pp. 77-84.

10) Wagenvoort, C.A., DuShane, J.W. \& Edwards, J.E. (1960) Hypertensive pulmonary arterial lesions as a late result of anastomosis of systemic and pulmonary circulation. Proc. Staff Meet. Mayo Clin., 35, 186-196.

11) Wagenvoort, C.A., Nauta, J., van der Schaar, Weeda, H.W.H. \& Wagenvoort, N. (1967) Vascular changes in pulmomary stenosis and tetralogy of Fallot studied in lung biopsies. Circulation, 36, 924-932.

12) Yamaki, S. \& Tezuka, F. (1976) Quantitative analysis of pulmonary vascular disease in complete transposition of the great arteries. Circulation, 54, 805-809.

13) Yamaki, S. \& Wagenvoort, C.A. (1981) Plexogenic pulmonary arteriopathy. Significance of medial thickness with respect to advanced pulmonary vascular lesions. Am. J. Pathol., 105, 70-75.

14) Yamaki, S., Dijk, H. \& Wagenvoort, C.A. (1980) Systemic arteries in experimental hypoxia in rats. J. Pathol., 131, 243-247.

15) Yamaki, S., Horiuchi, T., Miura, M., Suzuki, Y., Ishizawa, E. \& Takahashi, T. (1986) Pulmonary vascular disease in secundum atrial septal defect with pulmonary hypertension. Chest, 89, 694-698.

16) Yamaki, S., Horiuchi, T., Miura, M., Haneda, K., Ishizawa, E. \& Suzuki, Y. (1987) Secundum atrial septal defect with severe pulmonary hypertension - open lung biopsy diagnosis of operative indication -. Chest, 91, 33-38. 